Tropical Journal of Pharmaceutical Research May 2015; 14(5): 891-898

ISSN: $1596-5996$ (print); 1596-9827 (electronic)

(C) Pharmacotherapy Group, Faculty of Pharmacy, University of Benin, Benin City, 300001 Nigeria.

All rights reserved.

Available online at http://www.tjpr.org

Original Research Article

http://dx.doi.org/10.4314/tjpr.v14i5.20

\title{
Headspace Solid-Phase Microextraction Coupled with Gas Chromatography-Mass Spectrometric Analysis of Volatile Components of Raw and Stir-Fried Fruit of C. Pinnatifida (FCP)
}

\author{
Lian Zhong1, Yunwei Wang ${ }^{1}$, Wei Peng1, Yujie Liu', Jun Wan ${ }^{2,3}$, Shilong Yang1, \\ Liang $\mathrm{Li}^{1}$, Chunjie $\mathrm{Wu}^{1 *}$ and $\mathrm{Xia} \mathrm{Zhou}^{2}$ \\ ${ }^{1}$ College of Pharmacy, Chengdu University of Traditional Chinese Medicine, Chengdu, 611137, ${ }^{2}$ Life Science \& Engineering \\ College of Southwest Jiaotong University, Chengdu 610031, ${ }^{3}$ State Administration of Traditional Chinese Medicine Key \\ Research Laboratory of Traditional Chinese Medicine Processing Technology, Chengdu 610036, China
}

*For correspondence: Email: wucjcdtcm@163.com, wwangyidi@126.com; Tel: 86-028-61801001

\begin{abstract}
Purpose: To investigate the change of volatile components associated with odor of $C$. Pinnatifida (FCP) fruit and its stir-fried forms.

Methods: FCP fruit was stir-fried and monitored by an online-type and non-contact temperature measurement system (ONTMS). Headspace solid-phase microextraction (HS-SPME) coupled with gas chromatography-mass spectrometry (GC-MS) was used to analyze the volatile composition of raw FCP and its various stir-fried forms.

Results: The color of FCP turned darker with the stir-frying process. In all, 47 volatile compounds with contents $>1 \%$ were identified. The major volatile components were methyl acetate $(4.40 \%), n$-hexane (2.90\%), 2-methyl-furan (1.80\%), 3-methyl-butyraldehyde (3.64\%), hexanal (2.08\%), furaldehyde (5.77\%), and D-limonene (7.99\%) in raw FCP. Following stir-frying, the contents of furaldehyde, 5methyl-furaldehyde, methyl acetate, 2-methyl-butyraldehyde, D-limonene and 2-methyl-furaldehyde were altered significantly, which might have resulted in odor changes.

Conclusion: HS-SPME coupled with GC-MS is a rapid and eco-friendly method with the potential to analyze volatile compounds in raw and processed FCP.
\end{abstract}

Keywords: Crataegus pinnatifida, Stir-frying, Online-type and non-contact temperature measurement system, Headspace solid-phase microextraction, Volatile components, Odor

Tropical Journal of Pharmaceutical Research is indexed by Science Citation Index (SciSearch), Scopus, International Pharmaceutical Abstract, Chemical Abstracts, Embase, Index Copernicus, EBSCO, African Index Medicus, JournalSeek, Journal Citation Reports/Science Edition, Directory of Open Access Journals (DOAJ), African Journal Online, Bioline International, Open-J-Gate and Pharmacy Abstracts

\section{INTRODUCTION}

Crataegus pinnatifida (Hawthorn) belonging to the family of Rosaceae includes C. pinnatifida Bge. var. major N.E.Br. and C. pinnatifida Bge. The fruit of $C$. pinnatifida (FCP) is a valuable and important traditional Chinese medicine and natural food, mainly distributed in the north of China [1]. It was first documented in
Compendium of Materia Medica (bencaogangmu in Chinese) as an effective agent for treating dyspepsia and blood stasis [2]. Furthermore, FCP currently is commonly used to treat various diseases in Chinese folk medicine, including digestive disorders, blood stasis, cardiodynia, and hemafecia [1,2]. Previous phytochemical researches demonstrated that there were plenty of flavonoids, phenolic compounds, sugars, 
sugar alcohols, organic acids, and terpenes in FCP $[1,3]$. In addition, modern pharmacological researches have demonstrated that $\mathrm{FCP}$ possesses significant promotive effects on digestion [4], lipid regulative and antiatherosclerosis effects [5,6], anti-hypertensive effects [7], antioxidant [8] and antibacterial effects [9].

Based on the theory of traditional Chinese medicine (TCM) system, FCP should be processed before clinical application, and the processed products of FCP mainly include raw hawthorn and charred hawthorn [2,10]. Interestingly, it is proved that charred hawthorn possessed better therapeutic effect than raw hawthorn in treating digestive disorders [11]. Furthermore, the odor of the processed products of hawthorn is obviously different, and it has been suggested that odor change is one of the explanations for the different therapeutic effects. However, the link between changes in chemical composition and odor change has not been established.

In recent years, headspace solid phase microextraction (HS-SPME) has gained wide acceptance as an effective analytical technique for a wide variety of materials, including foods and drinks [12], especially for the aromatic materials. HS-SPME analytical method is ecofriendly and rapid compared with traditional analytical techniques, and it is performed by exposing a fiber coated with polymers to the headspace of samples without any solvent. The fiber selection is often based on the principle of "like dissolves like" [13].

The aim of the present study was to investigate variations in volatile profiles of raw FCP and its stir-fried forms using HS-SPME coupled with GCMS.

\section{EXPERIMENTAL}

\section{Materials}

FCP was purchased from the Hehuachi market of traditional Chinese medicine, and was identified by Professor Min Li (College of Pharmacy, Chengdu University of Traditional Chinese Medicine) and the voucher specimen (Voucher No. 2012010) deposited at the Herbarium Centre of Pharmacognosy, Chengdu University of Traditional Chinese Medicine, Chengdu, China. An online and non-contact temperature measurement system (ONTMS), invented by our research team, used to monitor temperature during the stir-frying process (Table 1) $[14]$.

Table 1: Stir-frying process conditions for FCP

\begin{tabular}{lccc}
\hline NO. & $\begin{array}{c}\text { Time } \\
(\mathbf{m i n})\end{array}$ & $\begin{array}{c}\text { Temperature } \\
\left({ }^{\circ} \mathrm{C}\right)\end{array}$ & Yield (\%) \\
\hline$S_{0}$ & 0 & & 100 \\
$S_{1}$ & 2 & $370 \pm 30$ & 99 \\
$S_{2}$ & 4 & $380 \pm 30$ & 96 \\
$S_{3}$ & 6 & $375 \pm 30$ & 96 \\
$S_{4}$ & 8 & $360 \pm 30$ & 93 \\
$S_{5}$ & 10 & $360 \pm 30$ & 92 \\
$S_{6}$ & 12 & $400 \pm 30$ & 90 \\
\hline
\end{tabular}

\section{HS-SPME analysis}

Approximately $3 \mathrm{~g}$ of pulverized sample, accurately weighed, was introduced into 20-mL headspace vial. The fibre was coated with 50/30 $\mu \mathrm{m}$ of Divinylbenzene-CarboxenPolymethylsiloxane (DVB/CAR/PDMS), which is used for the absorption of volatile compounds. The sample was maintained at $70{ }^{\circ} \mathrm{C}$ for $20 \mathrm{~min}$. During the sampling time, the sample was stirred at constant speed of $250 \mathrm{rpm}$. Following headspace extraction, SPME fibers were injected into the $\mathrm{GC}$ and remained in the $\mathrm{GC}$ inlet for 3 $\min$.

\section{GC-MS analysis}

Volatile analysis was performed on an Agilent 7890A gas chromatograph coupled with a 5975C mass selective detector (Agilent Technologies, USA). Compounds were separated on a DB-5MS column $(30 \mathrm{~m} \times 0.25 \mathrm{~mm}$ i.d., $0.25 \mu \mathrm{m}$ film thickness, Agilent Technologies). Injector temperature was $250{ }^{\circ} \mathrm{C}$, and the split ratio was 1:1. Nitrogen of high-purity $(99.999 \%)$ was used as the carrier gas at a flow rate of $1 \mathrm{~mL} / \mathrm{min}$. The GC oven temperature was programmed as follows: $40{ }^{\circ} \mathrm{C}$ for $5 \mathrm{~min}, 5{ }^{\circ} \mathrm{C} / \mathrm{min}$ to $215^{\circ} \mathrm{C}$. The interface temperature was $280{ }^{\circ} \mathrm{C}$, and the quadrupole temperature was set at $150{ }^{\circ} \mathrm{C}$. The mass spectrometer was fitted with an $\mathrm{El}^{+}$source operated at $70 \mathrm{eV}$ with a source temperature of $250{ }^{\circ} \mathrm{C}$, and mass spectra were recorded in the range of $\mathrm{m} / \mathrm{z} 20$ - 400 amu in the full scan acquisition mode. The electron multiplier voltage was $500 \mathrm{~V}$.

\section{Data analysis}

In the present study, volatile compounds were identified by comparing the mass spectra of the analytes with those of authentic standards from the NIST database with a resemblance > $85 \%$. In addition, the compounds were analyzed based on 2 criteria: (1) the possibility index was used to confirm the identified constituents with a value $>$ 
750 , (2) peak area relative to total peak areas > $1 \%$ (i.e., amount of individual components expressed as \% area of total peak areas).

\section{RESULTS}

\section{Stir-fried FCP monitored by ONTMS}

Figure 1 shows stir-fried FCP monitored by ONTMS in different processing time. The surface color of raw FCP is red and its pulpa brown or light brown. The color of stir-fried FCP turns darker gradually with the processing.

\section{Volatile compounds identified by HS- SPME/GC-MS}

The typical total ion chromatograms of the HSSPME/GC-MS are shown in Figure 2. The results of the HS-SPME/GC-MS analysis are summarized in Table 2.

\section{Volatile composition of raw FCP}

In all, 20 volatiles were identified in raw FCP, including 13 carbonyls, and 7 additional volatiles. The major components identified in the HS-
SPME extract of raw FCP were methyl acetate (4.40\%), n-hexane (2.90\%), 2-methyl-furan (1.80 \%), 3-methyl-butyraldehyde (3.64 \%), hexanal $(2.08 \%)$, furaldehyde $(5.77 \%)$, and Dlimonene (7.99 \%). Amongst these compounds, D-limonene possessed the highest content.

\section{Changes in volatile compounds during the stir-frying process}

HS-SPME/GC-MS indicated that a range of aldehydes, ketones, alcohols, aromatic hydrocarbons, furans and oxazoles were formed during the processing of stir-frying. To investigate how the contents of volatile compounds changed in FCP during the stir-frying process, the 6 main compounds (Figure 3) with a content > $2 \%$ (relative percentage content) were selected, including furaldehyde, 5-methyl-furaldehyde, methyl acetate, 2-methyl-butyraldehyde, Dlimonene and 2-methyl-furaldehyde. In addition, these 6 target compounds were selected as characteristic compounds of the stir-frying process, which might be the main contributors to odor change of FCP.

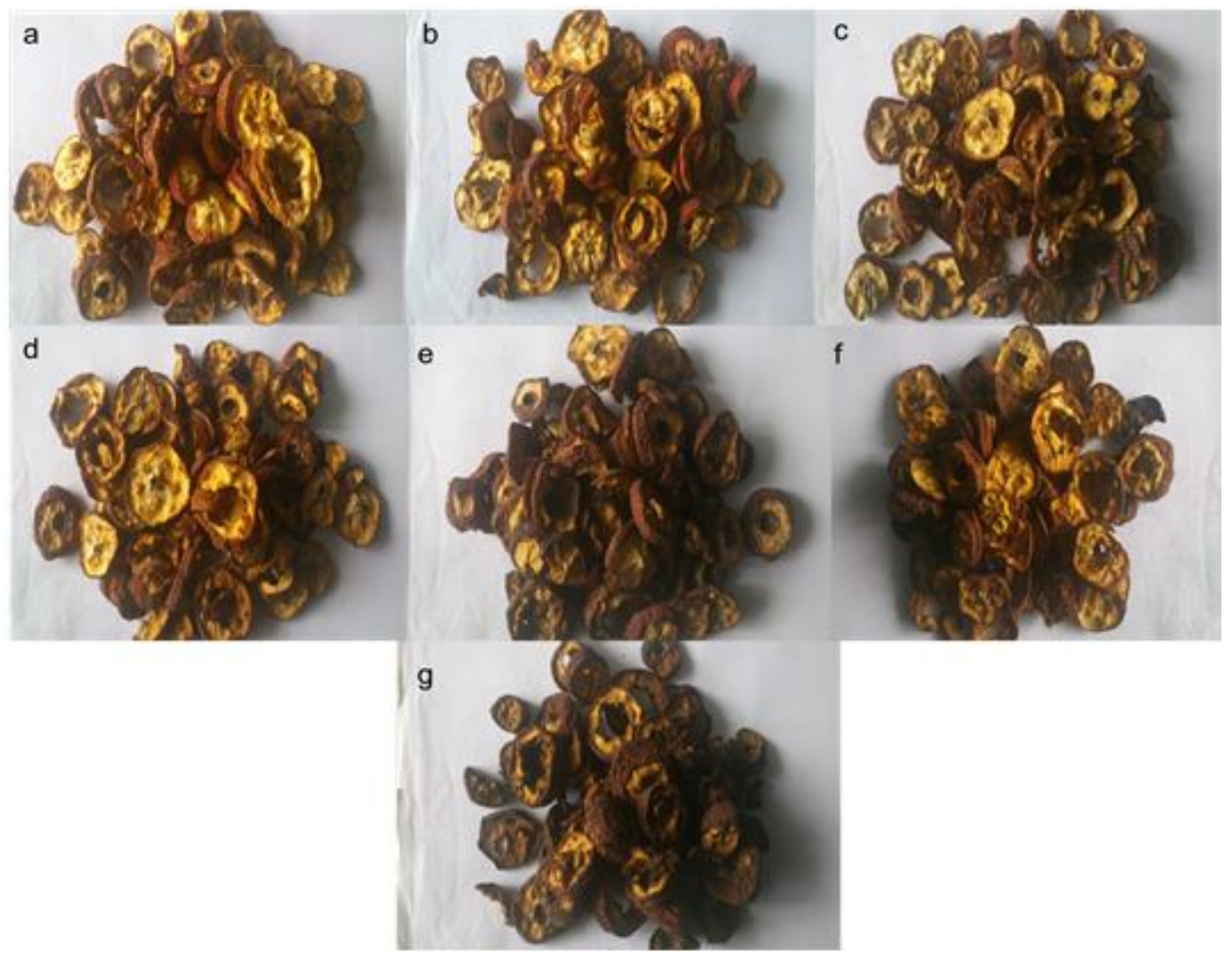

Figure 1: Stir-fried samples monitored by ONTMS collected at 0 min (a), 2 min (b), 4 min (c), 6 min (d), 8 min (e), $10 \min (f)$ and $12 \min (g)$, respectively 

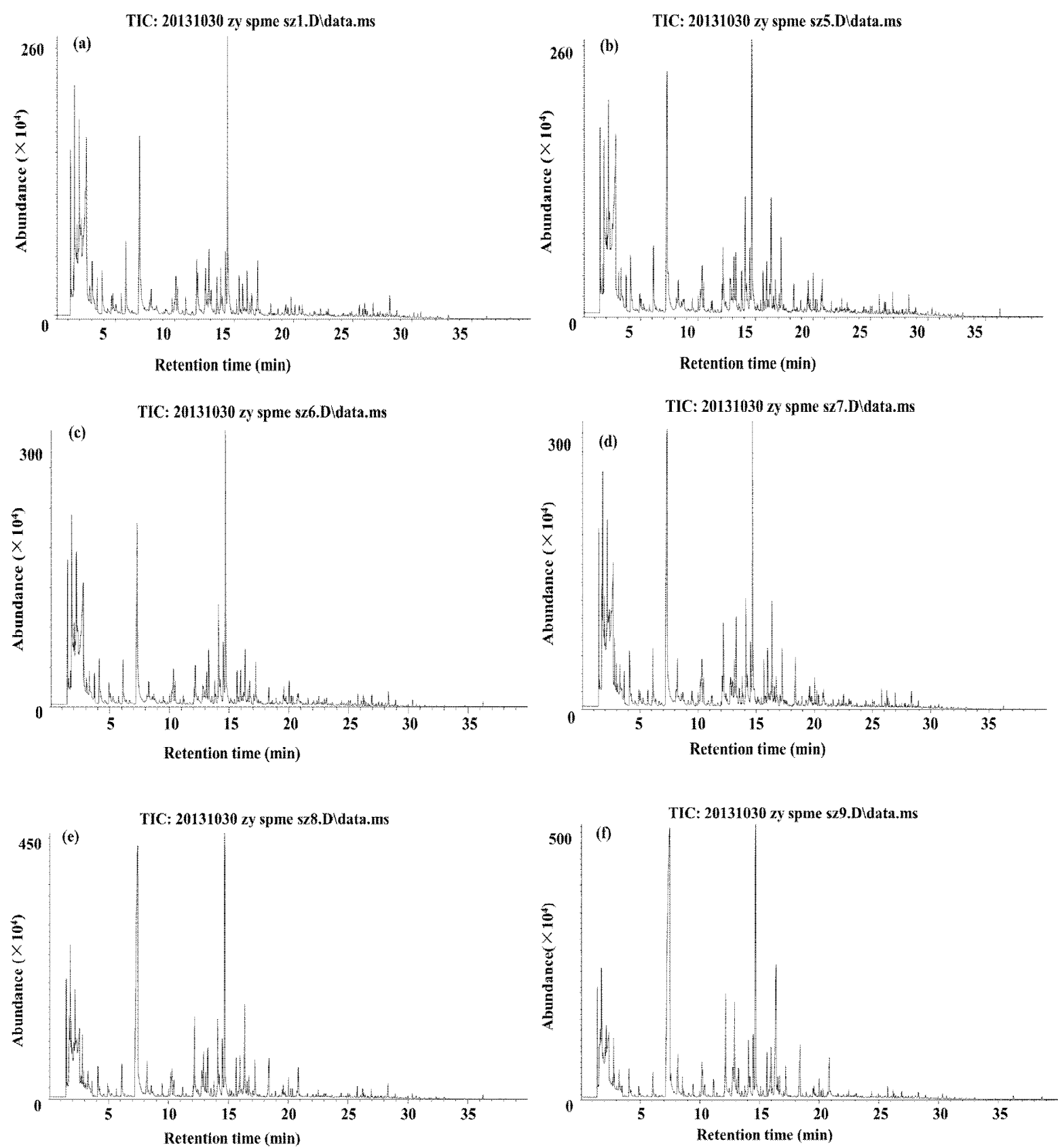

TIC: $20131030 \mathrm{zy}$ spme sz10.Didata.ms

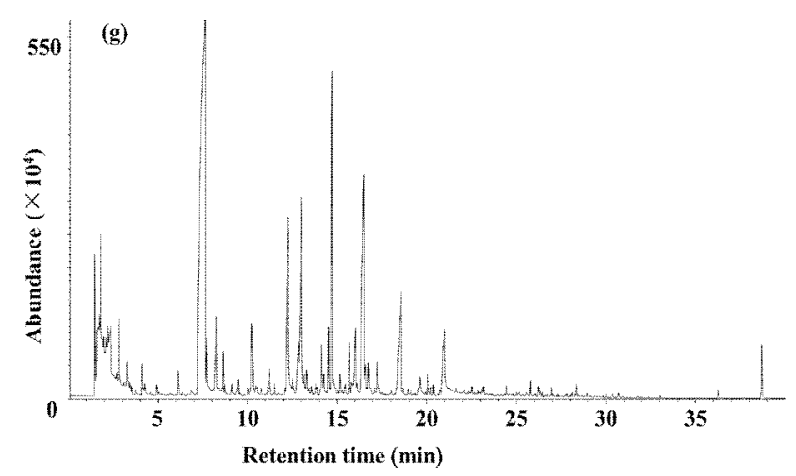

Figure 2: GC-MS total ion chromatogram of volatile components of the raw and processed products of FCP. a-g represented the raw FCP and its processed products stir-fried 2, 4, 6, 8, 10, 12 min, respectively 
Table 2: Chemical composition analysis of the volatile constituents of the stir-frying process of FCP

\begin{tabular}{|c|c|c|c|c|c|c|c|c|c|}
\hline \multirow{2}{*}{ RT (min) } & \multirow{2}{*}{ Compound } & \multirow{2}{*}{ Possibility } & \multicolumn{7}{|c|}{ Relative contents (\%) } \\
\hline & & & Raw & $2 \mathrm{~min}$ & $4 \mathrm{~min}$ & $6 \mathrm{~min}$ & $8 \mathrm{~min}$ & $10 \mathrm{~min}$ & 12min \\
\hline 1.712 & Acetone & 948 & -- & -- & -- & -- & -- & 1.38 & -- \\
\hline 1.745 & formic acid & 933 & -- & -- & -- & -- & -- & 1.41 & -- \\
\hline 1.797 & borane-methyl sulfide complex & 960 & 1.91 & 1.93 & 1.40 & 1.06 & 0.39 & -- & -- \\
\hline 1.806 & dimethyl sulfide & 952 & -- & -- & -- & 4.00 & 2.67 & -- & -- \\
\hline 1.823 & methyl acetate & 926 & 4.40 & 4.21 & 2.93 & 2.67 & 2.06 & 1.39 & -- \\
\hline 2.173 & n-hexane & 907 & 2.90 & -- & 2.36 & -- & -- & -- & -- \\
\hline 2.199 & 2-methyl-furan & 933 & 1.80 & 1.22 & 1.36 & 0.88 & 0.26 & -- & -- \\
\hline 2.224 & 2,3-dimethyl-1-butene & 726 & -- & 2.22 & -- & 1.88 & -- & -- & -- \\
\hline 2.233 & 2-methyl-octyl ester-2-propenoic acid & 677 & -- & -- & -- & -- & 1.26 & -- & -- \\
\hline 2.524 & 4-methyl-1,3-pentadiene & 938 & -- & -- & -- & 1.6 & 1.39 & -- & -- \\
\hline 2.644 & 2,3-dihydro-furan & 821 & -- & -- & -- & 2.30 & -- & -- & -- \\
\hline 2.652 & 2-butenal & 844 & 1.88 & 1.71 & -- & -- & -- & -- & -- \\
\hline 2.712 & 3-methyl-butyraldehyde & 800 & 3.64 & 3.71 & 3.91 & 4.03 & -- & -- & -- \\
\hline 2.823 & 2-methyl-butanal & 900 & 1.84 & 1.27 & -- & -- & -- & -- & -- \\
\hline 3.293 & Pentanal & 910 & 1.35 & -- & -- & -- & -- & -- & -- \\
\hline 4.114 & (E)-3-penten-2-one & 931 & 1.54 & 1.47 & 1.36 & 1.13 & -- & -- & -- \\
\hline 4.131 & $\begin{array}{l}\text { 1-[(1-oxo-2-propenyl)oxy]-pyrrolidine- } \\
\text { 2,5-dione }\end{array}$ & 724 & -- & -- & -- & 1.13 & -- & -- & -- \\
\hline 4.14 & 1-penten-3-one & 626 & 1.94 & -- & -- & -- & -- & -- & -- \\
\hline 6.114 & Hexanal & 905 & 2.08 & 1.41 & 1.4 & 1.30 & -- & -- & -- \\
\hline 7.226 & 5-methyl-2(3H)-furanone & 650 & -- & 1.30 & -- & -- & -- & -- & -- \\
\hline 7.261 & $\begin{array}{l}\text { 2,4-dihydro-5-methyl-3H-pyrazol-3- } \\
\text { one }\end{array}$ & 699 & -- & -- & -- & 3.30 & -- & -- & -- \\
\hline 7.303 & 5-methyl-3-isoxazolamine & 665 & -- & -- & -- & -- & 5.32 & -- & -- \\
\hline 7.321 & Furaldehyde & 933 & 5.77 & 6.81 & 8.45 & $\begin{array}{c}11.2 \\
3\end{array}$ & 18.95 & 18.52 & 23.87 \\
\hline 7.525 & 2-oxo-methyl butyrate & 750 & -- & -- & -- & -- & -- & 18.27 & -- \\
\hline 8.209 & 2-furanmethanol & 955 & -- & -- & -- & -- & -- & 1.02 & 1.15 \\
\hline 10.202 & $2(5 \mathrm{H})$-furanone & 890 & -- & -- & -- & -- & -- & -- & 1.43 \\
\hline 10.227 & 1-(2-furanyl)-ethanone & 953 & -- & -- & -- & -- & -- & -- & 1.43 \\
\hline 10.338 & Butyrolactone & 904 & 1.27 & 1.36 & 1.37 & 1.51 & -- & -- & - \\
\hline 12.083 & (Z)-2-heptenal & 904 & 1.09 & -- & - & -- & -- & -- & -- \\
\hline 12.16 & 5-methyl-2-furancarboxaldehyde & 954 & 1.50 & 1.71 & 1.47 & 2.01 & 2.37 & 2.30 & 3.09 \\
\hline 12.835 & 1-decylene-3-one & 805 & 1.75 & -- & -- & -- & - & -- & -- \\
\hline 12.852 & 1,2-glycol diacetate & 615 & -- & -- & -- & -- & -- & -- & 1.07 \\
\hline 12.937 & $\begin{array}{l}\text { 2,4-dihydroxy-2,5-dimethyl-3(2H)- } \\
\text { furan-3-one }\end{array}$ & 874 & -- & -- & -- & -- & 1.16 & 2.07 & 3.43 \\
\hline 13.014 & $\begin{array}{l}\text { D-alanine, N-butoxycarbonyl-dodecyl } \\
\text { ester }\end{array}$ & 702 & -- & -- & -- & -- & -- & -- & 3.37 \\
\hline 13.117 & 6-methyl-5-heptene-2-one & 933 & 1.60 & 1.11 & -- & -- & -- & -- & -- \\
\hline 13.271 & $2 \mathrm{H}$-pyran-2,6(3H)-dione & 797 & -- & 1.02 & -- & 1.51 & 1.06 & -- & -- \\
\hline 13.279 & 2,2,4,6,6-pentamethyl-heptane & 900 & -- & 1.02 & 1.27 & 1.50 & 1.06 & -- & -- \\
\hline 14.126 & ethyl acetate & 711 & -- & -- & 2.82 & -- & -- & -- & -- \\
\hline 14.502 & O-cymene & 956 & 1.52 & 1.09 & 1.52 & 1.14 & -- & 1.03 & -- \\
\hline 14.511 & 1-methyl-3-(1-methylethyl)-benzene & 943 & -- & -- & -- & -- & 1.38 & -- & -- \\
\hline 14.682 & D-limonene & 919 & 7.99 & 7.47 & 7.13 & 5.73 & 5.61 & 5.11 & 4.13 \\
\hline 15.973 & $\begin{array}{l}\text { dihydro-3-methylene-5-methyl-2- } \\
\text { furanone }\end{array}$ & 756 & -- & -- & -- & 1.11 & 1.11 & 1.13 & 1.24 \\
\hline 16.357 & 2,5-furandicarboxaldehyde & 837 & -- & -- & -- & -- & -- & -- & 1.12 \\
\hline 16.408 & 3-furancarboxylic acid methyl ester & 901 & -- & 2.03 & 1.72 & 1.82 & 2.56 & 3.53 & 5.61 \\
\hline 17.221 & Nonanal & 943 & 1.69 & 1.31 & 1.10 & 1.07 & -- & -- & -- \\
\hline 18.375 & $\begin{array}{l}\text { 2,3-dihydro-3,5-dihydroxy-6-methyl- } \\
\text { 4h-pyran-4-one }\end{array}$ & 892 & -- & -- & -- & 1.13 & 1.32 & 1.51 & 3.10 \\
\hline 20.897 & 5-hydroxymethylfurfural & 889 & -- & -- & -- & -- & -- & 1.12 & 2.02 \\
\hline
\end{tabular}




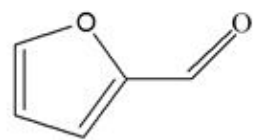

furaldehyde<smiles>CC(C)CC=O</smiles>

3-methyl-butyraldehyde 3-furancarboxylic acid methyl ester<smiles>COC(C)=O</smiles>

methyl acetate<smiles>CC1=CCC(C2CC2)CC1</smiles>

D-limonene

Figure 3: Chemical structures of the main constituents of volatile composition
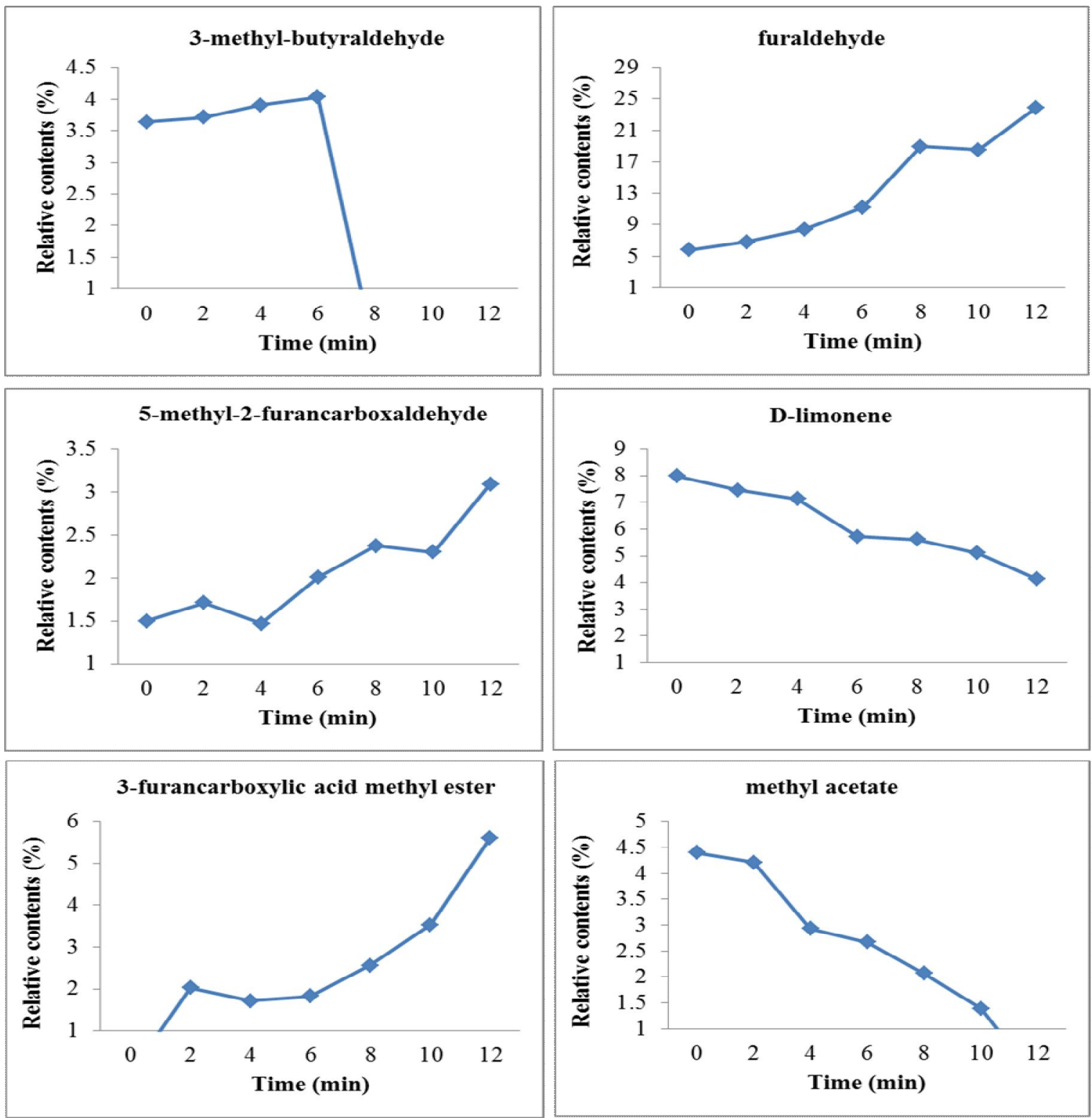

Figure 4: Contents change of the main constituents of volatile composition during the stir-frying process 
In the present investigation, the results showed that contents of 5-methyl-furaldehyde, furaldehyde, 3-furancarboxylic acid methyl ester increased gradually during the processing of FCP, whereas the contents of D-limonene, and methyl acetate decreased. For the contents of 3methylbutyraldehyde, it increased with the processing of stir-frying, then decreased (Figure 4).

\section{DISCUSSION}

The ONTMS provided an effective method to monitor the dynamic temperature and through this method we get ideal stir-fried FCP products. Aroma is one of the most important indexes to evaluate quality of aromatic foods [15] and Chinese herbal medicines [16]. The quality of aromatic medicines was often evaluated by GC or GC-MS method using essential oil extracted by steam distillation. Compared to this method, GC-MS following HS-SPME is a solvent-free, rapid and convenient method for the preconcentration, increasingly used for analysis of the volatile compounds from aromatic herbal medicines. To our best knowledge, the present investigation is the first work regarding the odor and chemical composition of the raw FCP and its stir-fried products. Our results suggest that the odor changes of different processed FCP might be mainly correlated with 5-methyl-furaldehyde, furaldehyde, 3-furancarboxylic acid methyl ester, 3-methyl-butanal, D-limonene and methyl acetate.

Maillard reaction is known as amino-carbonyl reaction or non-enzymatic browning reaction [17], which occurs during food processing, storage and produces a large number of Maillard reaction products, including non-volatile colored compounds of intermediate molecular mass, volatile compounds of low molecular mass, and complex brown substances of high molecular weight. These volatile compounds were mainly divided into 4 types, including $\mathrm{N}$-containing heterocyclic compounds, cyclic ketene-alcohol compounds, single-carbonyl compounds and multi-carbonyl compounds [18], which were mainly contributed to odor, flavor and color of foods. Previous investigations have demonstrated that the 5-hydroxymethyl furfural and its derivatives are the important and common intermediate products of the processing of traditional Chinese medicine mainly via Maillard reaction [19]. According to the present results, contents of 5-hydroxymethylfurfural and 5-methyl-furaldehyde were increased gradually during the processing, indicating that the odor changes might be related to the Maillard reaction. In addition, FCP is rich in sugar and amino acids in the aspect of chemical composition based on previous phytochemical investigations, which creates conditions for Maillard reaction.

\section{CONCLUSION}

The odor-active compounds and contents of volatile profiles of stir-fried FCP depend largely on stir-frying time. HS-SPME coupled with GCMS is a rapid and eco-friendly method to analyze volatile profiles of different stir-fried FCP. It is speculated that the change of these volatile compounds and odor may be caused by the Maillard reaction.

\section{ACKNOWLEDGEMENT}

This work was financially supported by the National Science \& Technology Pillar Program under the Twelfth Five-year Plan Period (no. 2012BAI29B11), and Fundamental Research Funds for Central Universities (no. 2682013CX035).

\section{REFERENCES}

1. Wu JQ, Peng W, Qin RX, Zhou H. Crataegus pinnatifida: Chemical Constituents, Pharmacology, and Potential Applications. Molecules 2014; 19(2), 1685-1712.

2. State Administration of Traditional Chinese Medicine. Chinese Material Medica, vol. 10. Science and Technology Press of Shanghai, Shanghai; pp 126132.

3. Liu RH, Shao F, Deng YQ, Ma ZL, Yu BY. The development of chemical compounds of Crataegus pinnatifida. J Chin Med Mater 2008; 31(7): 11001103.

4. Huang SS, Lin Y, Diao YP, Liu ZH, Zhen YH, Zhang HL. Effects of charred fructus Crataegi alcohol extract on contractility of isolated rat gastric and intestine muscle strips. Prog Mod Biomed 2009; 9(4), 612-614.

5. Li GH, Sun JY, Zhang XL, Yang ZL, Zhou C, Yang SB. Experimental studies on antihyperlipidemia effects of two compositions from hawthorn in mice. Chin Tradit Herbal Drugs 2002; 33(1), 50-52.

6. Liu J, Sun HB, Duan WG, Mu DY, Zhang LY. Maslinic acid reduces blood glucose in KK-Ay mice. Biol Pharm Bull 2007; 30(11), 2075-2078.

7. Yuan Y, Zhao J, Gao HJ, Wang $J \mathrm{H}$. Experimental study on effect of hawthorn on compounding hypertension and hyperlipoidemia rats. J Xinjiang Med Univ 2013; 35(1), 52-57.

8. Chen ZY, Yan MX, He BH. The Change and the immpact of IFHL on oxidative stress in the formation of NASH in rats. J Med Res 2007; 36(12), 33-36.

9. Qin, RX, Xiao KK, Li B, Jiang WW, Peng W, Zheng J, Zhou $H$. The combination of Catechin and Trop J Pharm Res, May 2015; 14(5): 897 
Epicatechin Gallate from Fructus crataegi potentiates $\beta$-Lactam antibiotics against Methicillin-resistant Staphylococcus aureus (MRSA) in vitro and in vivo. Int J Mol Sci 2013; 14(1), 1802-1821.

10. Ch PC. Chinese Pharmacopoeia (2010 ed.). vol. 1. Beijing: China Medical Science and Technology Press; pp 29-30.

11. Zhu CY, Zhang T, Xue HP, Ke Y. Concocts the method differently the Chinese hawthorn extraction oxidation resistance active research quite. Medical Information 2009; 1(9): 150-151.

12. Xiao L, Lee JY, Zhang G, Ebeler SE, Wickramasinghe N, Seiber J, Mitchell AE. HS-SPME GC/MS characterization of volatiles in raw and dry-roasted almonds (Prunus dulcis). Food Chem 2014; 151: 31 39.

13. García-Martín S, Herrero C, Peña RM, Barciela J. Solidphase microextraction gas chromatography-mass spectrometry (HS-SPME-GC-MS) determination of volatile compounds in orujo spirits: Multivariate chemometric characterization. Food Chem 2010; 118:456-461.

14. Liu YJ, Xu Y, Qiao HY, Ke X, Wu ZG, Sun T, Wu CJ. Online Monitoring for Strychnos Nux-vomica Parching in Sands and Chemical Compositional Analysis by
Ultra Performance Liquid Chromatography-Linear Trap Quadrupole-Orbitrap-Mass Spectrometry. Trop J Pharm Res 2014; 13(10): 1675-1680.

15. Chai $Q Q$, Wu BH, Liu WS, Wang LJ, Yang CX, Wang YJ , Fang JB, LiU YC, Li SH. Volatiles of plums evaluated by HS-SPME with GC-MS at the germplasm level. Food Chem 2012; 130(2): 432-440.

16. Xiong $Y$, Xiao $X H$, Yang $X Y$, Yan $D$, Zhang $C E$, Zou $H Q$, Lin $H$, Peng L, Xiao $X$, Yan $Y H$. Quality control of Lonicera japonica stored for different months by electronic nose. J Pharm Biomed Anal 2014, 91: 6872.

17. Gu FL, Abbas S, Zhang XM. Optimization of Maillard reaction products from casein-glucose using response surface methodology. LWT-Food Sci Technol 2009; 42(8): 1374-1379.

18. Zhou YQ, He FY, Yang YT, Shi JL,Deng KW, Tang Y, Liu WL. Research situation of Maillard reaction and its influence on research methods for processing and preparation process of Chinese materia medica. Chin Tradit Herbal Drugs 2014; 45 (1): 125-130.

19. M.A.J.S. van Boekel. Formation of flavour compounds in the Maillard reaction. Biotechnol Adv 2006; 24(2): 230-233. 